\title{
A GESTÃO DEMOCRÁTICA DE PROCESSOS COMO FORMA DE APLICAÇÃO DO NEGÓCIO JURÍDICO PROCESSUAL ATÍPICO NOS PROCEDIMENTOS DE INSOL VÊNCIA EMPRESARIAL
}

Edinilson Donisete Machado
Gustavo Pirenetti dos Santos

\section{RESUMO:}

O estudo analisa a teoria da gestão democrática de processos como uma forma de aplicação do negócio jurídico processual atípico nos processos de recuperação judicial, no intuído de promover o efetivo serviço jurisdicional, respeitando princípios constitucionais e a dignidade dos jurisdicionados, tornando o processo mais célere a partir do consenso. Adota-se a metodologia hipotético-dedutivo, utilizando-se de pesquisa bibliográfica como fonte de observação teórica e analise jurisprudencial. Assim, espera-se chamar a atenção dos operadores do direito para novas técnicas de resolução consensual de processos e distribuição equilibrada de ônus na recuperação judicial, possibilitando a efetividade da função instrumental do serviço jurisdicional.

Palavras-chave: Negócio Processual; Recuperação Judicial; Gestão Democrática de Processos; Processo Civil Constitucional; Divisão Equilibrada do Ônus;

\section{DEMOCRATIC PROCESS MANAGEMENT AS A FORM OF APPLICATION OF THE ATYPICAL PROCEDURAL LEGAL BUSINESS IN THE EMPLOYMENT INSOLVENCY PROCEDURES}

\begin{abstract}
:
This study analyzes the theory of democratic process management as an application of the atypical procedural legal transaction in judicial recovery processes, with the aim of promoting the effective judicial service and the dignity of the courts, making the process faster consensus. The hypothetical-deductive methodology has adopted, using bibliographical research as a source of theoretical observation and jurisprudential analysis. Thus, it has hoped to draw the attention of the operators of the law to new techniques of consensual resolution of processes and balanced distribution of burdens in the judicial recovery, making possible the effectiveness of the instrumental function of justice.
\end{abstract}

Keywords: Procedural Business; Judicial recovery; Democratic Management of Processes; Constitutional democratic process; Balanced Division of Ounus;

\footnotetext{
${ }^{1}$ Professor titular do Centro Universitário Eurípides de Marília-UNIVEM e da Universidade Estadual Norte do Paraná, na graduação e na pós-graduação. Coordenador do curso de graduação em Direito e Coordenador dos Programas Lato Sensu em Direito. Mestrado em Direito pela Universidade Estadual Paulista Júlio de Mesquita Filho (2000) e Doutorado em Direito pela Pontifícia Universidade Católica de São Paulo (2006). E-mail: ednilson@univem.edu.br

${ }^{2}$ Mestrando em Direito Tecnológico e Novos Direitos no Programa de Estudos Pós-Graduados em Direito do Centro Universitário Eurípides de Marília - UNIVEM, Bolsista CAPES/PROSUP (Coordenação de Aperfeiçoamento de Pessoal de Nível Superior); Pós-graduando em Processo Civil pela Universidade Presbiteriana Mackenzie. E-mail: gupirenetti@gmail.com
} 


\section{INTRODUÇÃO}

O entendimento adequado acerca de um instituto jurídico somente pode ser observado quando se conhece o contexto em que tal instituto está inserido. É o conhecimento e a compreensão de múltiplos fatores que originaram o instituto e, que permite ao interprete realizar de forma correta a interpretação e aplicação do sistema jurídico, a fim de que se possa extrair da norma o seu real e verdadeiro significado, adequando de forma completa sua eficácia no plano concreto.

Analisar o direito não se limita à simples leitura do texto de lei. A simples compreensão fria acerca dos diplomas e códigos legislativos dispensa qualquer preparo científico nas ciências jurídicas, bastando que o leitor tenha um nível razoável de conhecimento das regras de escritas para entender os termos ali expressos. Compreender e analisar o direito pressupõe entender o que está por trás do arcabouço da lei, levando em conta o contexto histórico, político, social, influenciado por correntes políticas e econômicas que determinam direta e indiretamente a finalidade e o objetivo da lei.

A Lei 13.105/2015 instituiu um novo Código de Processo Civil, totalmente remodelado a partir do conceito da mutua cooperação processual. Atribuindo assim, maior agilidade aos procedimentos, perpetrando maior eficácia à tutela jurisdicional entregue aos jurisdicionados.

Assim, o primeiro capítulo objetiva-se ao estudo da estrutura dos negócios jurídicos processuais atípicos, superando as hipóteses taxativas da legislação processual de 1973. Tal negociação permite o ajuste de vontades entre os sujeitos processuais, modelando o processo judicial as necessidades e expectativas.

Em seguida, partindo da evolução procedimental da negociação jurídica processual, busca-se analisar sua aplicação no processo de recuperação judicial a partir da crise empresarial e sua insolvência, bem como o mecanismo necessário para a preservação das empresas, configurando-se um instrumentos processual importantíssimo para sua função social, de maneira que, na exercício dessa qualidade, sejam concretizados os escopos sóciopolítico-jurídico do processo. 
Ao final, será possível ter uma análise crítica e científica sobre a possibilidade da aplicação e interpretação adequada dos dispositivos legais, propondo-se a adoção de um novo modelo de gestão processual democrático como espécie de negócio juridico processual que permita maior agilidade e democracia no processo decisório, garantindo sua eficiência por meio da consciência de que todos as partes que atuam no processo possuem um ônus de que devem se desincumbir, para que a finalidade do sistema juridico da recuperaçao possa atingir os resultados esperados. Para tanto, os credores e os devedores deverão equilibradamente suportar o ônus materiail e processual para que seja possivel a preservaçao dos resultados positivos que decorrem da permanencia da atividade empresarial saudável, bem como seus reflexos socias e politicos.

O presente estudo estabelece como cerne o método discursivo hipotético-dedutivo para atribuir, a partir de análise bibliográfica e jurisprudencial, estabelecer a conexão entre a aplicação dos negócios jurídicos processuais atípicos por meio da teoria da gestão democrática de processos, à luz de princípios, garantias constitucionais, leis infraconstitucionais, doutrina e jurisprudência.

No mais, esta analise teórica não tem a pretensão de esgotar o tema em si mesma, pretende-se, pelo contrário, contribuir para as reflexões de modo a obtermos uma compreensão geral do direito da empresa em crise, inserindo-a no novo contexto processual da gestão democrática de processos, objetivando a importância do assunto para a garantia do direito interno como instrumento de cooperação processual.

\section{NEGÓCIO JURÍDICO PROCESSUAL ATÍPICO}

O presente capitulo tem como objetivo analisar brevemente a estrutura dos atos e negócios jurídicos para então, identifica-lo na estrutura sistemática do procedimento de insolvência empresarial. A partir daí é possível entender a teoria da gestão democrática de processos como uma forma de aplicação da nova sistemática negocial trazida pelo novo Código de Processo Civil.

O código de processo civil anterior adotou de forma exaustiva a classificação de atos processuais como sendo exclusivamente atos das partes integrantes dos processos e os atos dos órgãos jurisdicionais. De certa forma, esta classificação se tornou útil para que o sistema 
recursal fosse organizado na sistemática dos atos que seriam recorríveis e os atos não recorríveis (CHIOVENDA, 1998, p. 33).

Uma concepção mais subjetiva de atos processuais surgiu posteriormente, atribuindo-lhes certa tipologia a partir da constatação de quem seriam os sujeitos processuais que praticariam determinado ato, por conseguinte, analisando os efeitos dele decorrentes (GOLDSCHMIDT, 2006, p. 297-300).

Embora a concepção de Goldschmidt foi recebida por inúmeros processualistas modernos, foi a partir da classificação técnica proposta por Carnelutti que os atos jurídicos foram observados prisma da eficácia técnica e da eficácia jurídica (CARNELUTTI, 2000, p. 125-130). Assim, os atos processuais foram classificados conforme seus efeitos, sua finalidade e, por fim, a estrutura.

O primeiro, delimita os atos de acordo com os efeitos jurídicos constitutivos, extintivos, impeditivos e modificativos do direito. O segundo, permite aos atos contornos finalísticos, isto é, quando há uma relação entre a finalidade do ato e os efeitos jurídicos do mesmo, é o caso da transcendência, o que não ocorre nas situações em que o ato não implica efeitos jurídicos, sendo considerado como intranscendente. Por fim, os atos processuais classificados quanto a sua estrutura, se estes geram ou não mudanças a um fato pré-existente, e quantos atos são necessários para que haja alguma mudança (CARNELUTTI, 2000, p. 132140).

Dentro de todo o universo relatado, para delimitar-se ao tema proposto, é necessário focar-se apenas na classificação quanto a finalidade, pois o negócio processual consubstanciase como subespécie da finalidade transcendente dos atos. Assim, para que um ato seja considerado como um negócio processual, é necessário que ele constitua um exercício de poder e que seja um direito subjetivo, aliado ao interesse da parte que o realizou. Desta forma, o negócio se perfaz na vontade das partes, isto é o "querer" do interessado no processo (CARNELUTTI, 2000, p. 122-124).

Outrossim, nas palavras de Didier Jr (2017, p. 420-422) “o processo é um conjunto de atos teologicamente organizados para a pratica de um ato final, a decisão". Desta forma, quando um fato jurídico, que é toda ocorrência humana ou natural que gera efeitos jurídicos, se torna um suporte fático para uma norma jurídica processual, tem-se então a existência de um fato jurídico processual. 
Desta forma, quando se fala de um fato jurídico voluntário, fala-se em negócio processual, cujo suporte fático é o poder das partes processuais em regular, dentro dos limites fixados no próprio ordenamento jurídico, certas situações processuais ou procedimentais (DIDIER JR, 2017, p. 425).

Assim, sob este prisma, pode-se dizer que negócio jurídico é uma fonte de norma processual, podendo até mesmo vincular o Estado-Juiz, que deve cumprir normas jurídicas validas, inclusive as convencionadas, como é o caso dos inúmeros negócios processuais cujo interesse do presente estudo consubstancia-se no negócio processual que tenha por objeto o próprio processo (DIDIER JR, 2017, p. 425-426).

O negócio juridico é um ato pelo qual, em razão do autorregramento da vontade, o sujeito manifesta vontade visando à criação, modificação ou extinção de situações jurídicas previamente definidas no ordenamento juridico. A vontade não cria efeitos; compõe o suporte fático, que, após a incidência da regra jurídica, produz o fato juridico do qual derivam os efeitos. (NOGUEIRA, 2011, p.120).

Segundo Carnelutti, há correlação entre o direito subjetivo e o negócio juridico, enumerando duas características do negócio processual. A primeira, o negócio juridico processual seria enxergado como um ato de exercício de um poder cuja a finalidade é determinar uma conduta a partir de um efeito juridico. A segunda, decorrente da primeira, pois o negócio juridico acabaria sendo $\mathrm{u}$ poder juridico de exercício subjetivo (CARNELUTTI, 2000, p. 125).

Neste interim, o caput do art. $190^{3}$ do Código de Processo Civil é considerado por Didier Jr como uma cláusula geral da qual se pode extrair o princípio da atipicidade da negociação processual, permitindo a concretização do autorregramento da vontade no processo. Desta cláusula geral, admitem-se inúmeras espécies de negócios jurídicos atípicos (DIDIER JR, 2017, p. 429).

Estes negócios jurídicos processuais atípicos poderão dispor a respeito do ônus, faculdades, deveres, poderes e até mesmo atos processuais, redefinindo-os em sua forma ou ordem de realização, situação que não se confundo com o objeto litigioso, regido pela autocomposição. Este negócio juridico processual atípico terão como objeto o próprio processo (DIDIER JR, 2017, p. 430).

\footnotetext{
${ }^{3}$ Art. 190. Versando o processo sobre direitos que admitam autocomposição, é lícito às partes plenamente capazes estipular mudanças no procedimento para ajustá-lo às especificidades da causa e convencionar sobre os seus ônus, poderes, faculdades e deveres processuais, antes ou durante o processo.
} 
A eficácia deste procedimento se perfaz no art. 200 da mesma disciplina processual civil, atribuindo eficácia imediata como regra geral. O juiz somente limitará ou negará a aplicação do negócio processual se constarem quaisquer invalidades que impeçam que as regres convencionadas se apliquem nos planos da existência ou da validade. De forma que, esta nova concepção adotada ao processo civil brasileiro passou a admitir que as partes possam comandar determinadas formas procedimentais que melhor atinjam seus objetivos em comum (TALAMINI, 2016, p. 6-7).

A mudança efetivou o entendimento de que o processo tem como objetivo fundamental a proteção do direito material, seja ele qual for, de modo que os titulares de determinadas situações processuais são as partes integrantes da lide, e não o órgão jurisdicional. Portanto, como titulares diretos do interesse processual, garantiu-se maior mobilidade e adequabilidade aos fatos jurídicos processuais. Ora se as partes poderão autocompor a respeito do direito material, poderão também convencionar o andamento processual que lhe melhor assistirem (TALAMINI, 2016, p. 8).

Por se tratar de uma cláusula geral descrita no art. 190 da legislação processual, não se pode falar em limites para os negócios processuais objetos do estudo, desde que não violem preceitos legais, constitucionais, principiológicos, validamente aplicados nas esferas do direito, não atingindo terceiros alheios a relação processual (TALAMINI, 2016, p. 8). De igual forma, podem as partes incluírem o juízo nos negócios processuais atípicos, tanto como fiscal imediato da validade do negócio, como gestor processual permeando maior agilidade aos atos em razão da diminuição da litigiosidade (DIDIER JR, 2017, p. 432).

Para que a negociação seja plenamente eficaz, ser-lhe-á necessário a adoção de das seguintes diretrizes: a) não havendo regra que imponha interpretação restritiva, deve-se permitir o negócio processual; b) a negociação processual não poderá interferir no mérito de direitos indisponíveis que não admitem autocomposição; c) as regras de ilicitude do objeto no direito privado se aplicam aos negócios processuais; d) não se admite negócio processual que afaste regra processual que proteja direito indisponível; e) a negociação não poderá ser abusiva e; f) as partes poderão definir outros deveres e sanções dos já existentes no rol legal de sansões (DIDIER JR, 2017, p. 437-440).

Desta forma, o direito processual civil e a doutrina buscaram tutelar e regular as regras de negociações processuais a fim de respeitar o direito ao autorregramento da vontade, 
permitindo às partes, detentoras do principal interesse sobre o direito material, articulem para que o procedimento se adeque às suas vontades.

Melhor oportunidade seria, se os procedimentos pudessem ser aplicados nos processos de insolvência empresarial, o que de fato será objeto de estudo a seguir, onde juristas empresariais desenvolveram uma atípica negociação processual para que, o ônus do dualismo pendular na relação credor-devedor seja superado, a fim de que as partes assumam a qualidade negocial do sistema de insolvência, bem como participem da solução mais justa e eficaz na recuperação ou liquidação das empresas.

\title{
3. SISTEMA JURÍDICO DE RECUPERAÇÃO DA INSOLVÊNCIA EMPRESARIAL
}

O instituto da recuperação superou por completo a antiga concordata, dando maior enfoque à preservação da empresa, a Lei 11.101/2005 consagrou um novo instrumento processual para a recuperação econômica da empresa em crise, garantindo o prosseguimento das atividades por ela desenvolvidas. Assim, o art. 47 da lei em questão, dispôs:

\begin{abstract}
A recuperação judicial tem por objetivo viabilizar a superação da situação de crise econômico-financeira do devedor, a fim de permitir a manutenção da fonte produtora, do emprego dos trabalhadores e dos interesses dos credores, promovendo, assim, a preservação da empresa, sua função social e o estímulo à atividade econômica.
\end{abstract}

A recuperação judicial manifesta-se como instrumento processual, possuindo procedimento corretivo cujo objetivo é o afastamento do estado de pré-falência da empresa reestruturação e reorganização de suas atividades e administração, conferindo-lhe tratamento especiais para que a crise pela qual foi submetida seja completamente superada, configurando sua preservação por meio da renovação da viabilidade econômica da atividade exercida (MARTINS, 2016, p. 130).

Com a recuperação judicial, o devedor insolvente possui a possibilidade de garantir sua sobrevivência ao se dirigir até o estado-juiz, para que este convoque todos os credores, onde será apresentado um plano econômico de viabilidade, reestruturando a empresa em quebra, submetendo o plano à aprovação dos credores reunidos, para que, corrijam, adequem ou rejeitem o plano (DINIZ, 2008, p. 621). Assim, o ordenamento jurídico brasileiro conferiu à recuperação judicial uma natureza jurídica contratual, pois depende diretamente da 
autorização dos credores, delegando-os o poder-dever sobre o plano de Recuperação (MARTINS, 2016, p. 130).

A Recuperação possui alguns requisitos para que possa ser aplicada a uma sociedade empresária, tanto que no artigo $2^{\circ}$ da Lei $\mathrm{n}^{\circ} 11.101 / 2005$, há a exclusão de alguns tipos empresariais de seu rol de aplicabilidade, são elas:

"As empresas públicas, sociedades de economia mista, instituições financeiras, as cooperativas de crédito, as administradoras de consórcio, as entidades de previdência complementar, as sociedades operadoras de planos de assistência à saúde, as seguradoras, as sociedades de capitalização e outras entidades legalmente equiparadas as outras. " (TOMAZETTE, 2012, p.60).

Às instituições aptas a proporem recuperação judicial, são exigidos requisitos para que o pedido seja formulado, visando a comprovação da verossimilhança de viabilidade econômica e seriedade no processo, sendo eles: 1) o exercício regular das atividades há mais de dois anos; 2) Não ser falido, e se falido, que as obrigações já tenham sido extintas; 3) Não ter obtido recuperação judicial a menos de 5 anos; 4) Não ter obtido Recuperação Judicial com base em plano especial a menos de 8 anos e, 5) Não ter sido condenado por crime falimentar, nem possuir sócio controlador ou administrador condenado por crime falimentar. (TOMAZETTE, 2012, p.60).

Não havendo vícios ou erros na petição inicial da recuperação, o Juiz encarregado dará procedência ao pedido, iniciando-se o processamento da recuperação. O despacho judicial não confere a empresa os benefícios da recuperação, apenas determina o início do procedimento que avaliará a viabilidade do pedido, além de nomear o administrador judicial ${ }^{4}$, suspender o prosseguimento de execuções contra a empresa insolvente, retirar as certidões negativas para que o devedor continue sua atividade e intimar o Ministério Público para fiscalizar o procedimento (COELHO, 2013, p. 433-434).

\footnotetext{
4 "O administrador judicial deve ser pessoa idônea, preferencialmente advogado, economista, administrador de empresas, contador ou pessoa jurídica especializada. [...] O administrador judicial tem sempre a função de fiscalizar a sociedade requerente, presidir a Assembleia de Credores e proceder à verificação dos créditos. Se não houver Comitê, ele também exerce as funções desse órgão. Finalmente, se o juiz tiver determinado o afastamento da administração da empresa em recuperação, caberá ao administrador judicial geri-la enquanto não for escolhido o gestor judicial pelos credores. " COELHO, Fabio Ulhôa. Curso de direito empresarial: contratos, falência e recuperação judicial, volume 3. - 14 Ed. São Paulo: Saraiva, 2013.
} 
Por conseguinte, a sociedade empresária ou o empresário deverão apresentar o plano de recuperação no prazo de 60 dias da data de publicação da decisão de deferimento do processo, sob pena de ter o pedido de recuperação sofrer convolação em falência (TZIRULNIK, 2005, p.116).

O Plano deverá conter em seu relatório a discriminação pormenorizada dos meios de recuperação a serem aplicados à empresa, a demonstração da viabilidade econômica da atividade exercida, realizado por um perito, bem como o laudo econômico-financeiro e o de avaliação dos bens da sociedade empresaria (NEGRÃO, 2007, p.173)

Nesta diapasão, o plano de recuperação judicial é a peça instrumental de maior primazia para o processamento do pedido, pois, se de fato ele for elaborado rigorosamente com primor técnico, atendendo as limitações e aspersões da empresa, poderá quase que certamente constituir-se como garantia da sustentabilidade e superação da crise, todavia, se o mesmo destoar-se por completo da realidade fática da sociedade empresaria, bem como não levar em conta a realidade econômica vivida pelo mercado no momento da crise, o plano será ineficaz, implicando na convolação da recuperação em falência (MARTINS, 2016, p.153).

Outrossim, a vontade dos credores precisa ir de encontro com a vontade da empresa devedora, pois a natureza jurídica da recuperação é a de um acordo consensual entre as partes, de modo que o devedor toma a iniciativa e apresenta o plano, mas este só produzirá seus efeitos se recebido e aprovado pelos credores, por esta razão, todos os credores devem ter a oportunidade de se manifestarem sobre o plano recuperacional (TOMAZETTE, 2012, p.201).

Devido à natureza negocial do acordo, os credores poderão fazer objeções e modificações no plano de recuperação proposto pela empresa devedora, desde que decorrido o prazo de trinta dias da publicação do edital de credores, devendo fundamentar a objeção alegando ausência de requisitos legais, ou então a inviabilidade técnica do plano, bem como a imprecisão dos laudos técnicos, a existência de qualquer tipo de crime ou fraude falimentar, devendo o juiz receber ou não a objeção após analisá-la (NEGRÃO, 2007, p.174).

Caso haja objeção ao plano apresentado, o juiz convocará a assembleia geral de credores para que deliberem acerca do plano de recuperação, marcando dada, local e horário, não excedendo 150 dias do deferimento do processamento de recuperação. Durante a assembleia geral, a Lei $\mathrm{n}^{\circ}$ 11.101/2005 deixa claro o poder de deliberação dos credores, podendo debater, discutir, modificar, alterar e por fim, votar a aprovação ou não do plano (MAMEDE, 2011, p.161/164). 
Após as discussões, a assembleia votará o plano de recuperação que, caso não haja qualquer nulidade da assembleia e o plano de recuperação for rejeitado pela maioria dos credores, o juiz decretará a falência do empresário ou da sociedade, todavia, se o plano for aprovado pela maioria dos credores, o juiz concederá o pedido de recuperação judicial, alterando a situação jurídica da empresa por completo (MAMEDE, 2011, p.166/176), vinculando todos os credores à decisão judicial, mesmo que alguns não concordem, posto que a vontade deliberativa da massa de credores, isto é, a maioria deles é suficiente para vincular a vontade de todos (TOMAZETTE, 2012, p.220).

Consequentemente, os efeitos da decretação da recuperação judicial aos credores são: 1) submissão de todos os créditos existentes na data do pedido, mesmo os que não estiverem vencidos; 2) exclusão do plano, os credores com garantia fiduciária de moveis ou imóveis, arrendadores mercantis, contratos de venda e compra com clausula de irrevogabilidade, irretratabilidade ou venda com reserva de domínio, além dos créditos de natureza tributária, ações trabalhistas e execuções ficais; 3) conservação dos direitos dos credores e, 4) concessão de prerrogativas especiais a créditos trabalhistas (DINIZ, 2008, p. 629).

Aprovado o plano e, surtido os efeitos da sentença que, constitui-se como um título executivo judicial, dá-se início o processamento final, isto é, a fase de execução, onde os termos do plano serão aplicados ao empresário ou sociedade empresária devedora (COELHO, 2013, p.73), ficando este, sob observação, devendo cumprir tudo que foi proposto no plano, buscando validar sua confiabilidade no que foi estabelecido no plano (TOMAZETTE, 2012, p.228).

Outrossim, ainda que não tenha cessado as obrigações do empresário e da sociedade empresária, a recuperação possui um prazo máximo de duração, isto é, dois anos contados da decisão da concessão, de acordo com o artigo 61 da Lei $\mathrm{n}^{\circ} 11.101 / 2005$, visando reduzir o ônus da manutenção da recuperação por tempo indeterminado que, por meio de sentença, o juiz determinará a extinção do processo, a remuneração do Administrador Judicial e, consequentemente o seu afastamento da fiscalização das atividades da empresa (TOMAZETTE, 2012, p.230).

Neste passo, o Estado bem como o mercado, interessados na preservação da empresa cuja função social já foi explanada, disponibilizou o instituto da recuperação judicial como meio processual e instrumental para garantia e solução dos conflitos nas relações entre 
devedores, credores, trabalhadores e todos os sujeitos de direito contidos nas relações satélites à empresa em crise.

A recuperação judicial configura-se um instrumento processual, possuindo procedimento corretivo cujo objetivo é afastar o estado de pré-falência da empresa, restaurando e reorganizando suas atividades e administração, conferindo-lhe tratamento especiais para superação da crise, preservando sua existência por meio da renovação da viabilidade econômica da atividade exercida (MARTINS, 2016, p. 130).

Ao ser dado à empresa a oportunidade de recuperar-se por meio do processo judicial antes da decretação de sua falência, permite-se a permanência de sua atividade econômica que só tem a acrescentar ao mercado, às relações sociais, ao desenvolvimento econômico próprio e dos credores. Passamos então a última análise do estudo, as novas teorias acerca do processamento da recuperação judicial por meio da gestão democrática do processo e da divisão equilibrada do ônus.

\section{DA GESTÃo DEMOCRÁTICA DOS PROCESSOS COMO FORMA DE NEGÓCIO JURÍDICO PROCESSUAL ATÍPICO}

O processo ao longo dos anos vem sofrendo significativas reformas, teoria após teoria, os sujeitos da relação processual sofrem alterações. Uma das principais teorias de processo desenvolvidas foi a de Oskar von Bülow, enquadrando o processo como uma relação jurídica que se desenvolve como um embrião e, como está em constante movimento, gradativamente se desenvolve alternando entre as partes da relação jurídica (BÜLOW, 2003, p. 06-07).

Nesta visão de relação jurídica que se desenvolve entrelaçando as partes, surge para cada um dos participantes, a existência de ônus, deveres, direitos, faculdades e sujeições que, materializam-se, no contexto da recuperação judicial, numa relação trilateral, envolvendo o magistrado, o devedor e os credores (BUENO, 2015, p. 77).

Quando se fala em recuperação judicial de empresas, conforme explorado anteriormente, o modelo de recuperação brasileiro foi inspirado pela reforma dos sistemas jurídicos de insolvência dos Estados Unidos, trazido a nós por meio da Lei 11.101/2005 que instituiu a divisão equilibrada de ônus entre o devedor e os credores, para que se possa obter 
os benefícios econômicos e sociais que a empresa em recuperação pode ensejar (COSTA, 2015, p. 19).

Diante da distribuição equilibrada do ônus, pode-se concluir duas coisas: a primeira, é que a empresa submetida ao processo de recuperação judicial terá que assumir o ônus a que lhe for atribuída no processo, agindo adequadamente no tocante ao processo e ao desenvolvimento da atividade empresarial; a segunda, é que o sentido da recuperação somente subsiste se atendido os benefícios sociais e econômicos da continuidade da atividade exercida pela empresa, como a manutenção dos postos de trabalho, rendimentos, tributos, entre outros. (COSTA, 2015, p. 19).

Assim, Daniel Carnio Costa convenciona o Princípio da divisão equilibrada do ônus na recuperação judicial, alternando o ônus ora entre o devedor em recuperação, ora entre os credores, assim dispondo:

A recuperação judicial deve ser boa para o devedor, que continuará produzindo para o pagamento de seus credores, ainda que em termos renegociados e compatíveis com a situação econômica. Mas também deverá ser boa para os credores, que receberão os seus créditos, ainda que em novos termos e com a possibilidade de eliminação deste prejuízo no médio ou longo prazo, considerando que a recuperanda continuará a negociar com seus fornecedores. (COSTA, 2015, p.23)

Desta forma, a empresa submetida ao procedimento de recuperação, recebe toda a proteção do ordenamento jurídico em função do ônus suportado pelos credores, que direta e indiretamente, financiarão a empresa por um período de tempo, restando à empresa buscar de toda a forma preservar os benefícios tutelados pelo instituto da recuperação. Tal distribuição equilibrada é de suma importância para aplicação do procedimento (COSTA, 2015, p. 65).

Ocorre que, a dinâmica alternativa entre credor e devedor, ao longo das mudanças legislativas ocasionaram o chamado por Fabio Comparato de dualismo pendular do interesse dos credores ou dos devedores, de modo que, a lei ora protegia com mais rigor o credor e ora protegia o devedor com mais esmero, alternando de um polo a outro como um pêndulo nas relações do direito material (COSTA, 2015, p. 33).

No entanto, Daniel Carnio Costa propõe a superação do dualismo pendular, posto que esse tem se tornado deficiente para renovação do direito concursar da atualidade, devendo deslocar-se o foco da interpretação da Lei 11.101/2005 para a verdadeira busca da utilidade e eficiência dos institutos nela consagrados (COSTA, 2015, p. 33). 
Ora, se de início a lei de recuperação judicial e falência foi instituída visando a proteção do devedor em crise em razão dos credores, quando o sistema de recuperação do insolvente mostra-se insuficiente para satisfazer os interesses dos credores, o sistema pendular desaba, perdendo sua eficácia, posto que os credores não optarão mais pelo instituto dada sua ineficiência, e assim, o bem jurídico tutelado, isto é a empresa em crise (COSTA, 2015, p. $34)$.

Diante da atual interpretação do direito concursal brasileiro, resta aos aplicadores do direito superar o dualismo pendular que recorrentemente alterna entre os interesses dos credores e devedores, buscando-se a correta interpretação e finalidade da Lei 11.101/2005, preservando-a em razão dos benefícios sociais de sua preservação e que dela resultam (COSTA, 2015, p. 34).

Assim, nota-se um alinhamento com a busca pela vontade concreta do direito, que se perfaz por meio do processo, superando o dualismo pendular que objetiva apenas a preservação do direito de um dos polos alternadamente para, evoluir à um direito que não apenas busque a sua aplicação no caso concreto, mas que efetivamente direcione a busca pela eficiência do procedimento como instrumento de garantia de direitos, não somente privamos, mas também sociais e abrangentes (DINAMARCO, 2001, p.132).

A correta interpretação, bem como a boa aplicação do instituto jurídico, portanto, não serão obtidos com a simples leitura e aplicação do texto normativo (COSTA, 2015, p. 35). Para tanto, o processo tem adquirido cada vez mais um escopo social, buscando a manutenção do equilíbrio econômico, sendo cada vez mais utilizado como instrumento para recompor a ordem jurídica, social e política (OLIVEIRA NETO, 2015, p. 232).

Deve-se ter em vista, ainda, que o direito comporta diversas interpretações razoáveis e possíveis, mas o que vai determinar o acerto de determinada interpretação serão as consequências econômicas e sociais obtidas com a aplicação da norma e que estejam em consonância com os fundamentos de existência da determinada lei (COSTA, 2015, p. 35).

O sistema de recuperação, ainda que novo no ordenamento jurídico brasileiro, é essencial para a reestruturação e aprimoramento do sistema socioeconômico do país, devido à grande importância que a empresa representa ao senário macro e microeconômico. Por isso, há a necessidade que o instituto seja aplicado em sua plena eficácia, de forma transparente, zelando pelo interesse social (COSTA, 2015, p. 44). 
Cabendo assim, ao juiz e ao administrador judicial a melhor forma de administrarem o andamento processual da recuperação, não utilizando o instituto de qualquer forma, mas visando atender os anseios sociais, bem como superar o dualismo pendular existente entre credores e devedores, controlando judicialmente a relação jurídica que, até o presente momento, vinha sendo observado como meramente negocial e de pouco intervencionismo estatal (MARTINS, 2016, p. 130).

Deve-se repensar a forma tradicional de gestão desse tipo de processo, considerando que a burocracia judicial tem sido um dos principais fatores a colaborar com a falta de eficiência da prestação jurisdicional. [...] Processo ineficaz, que não garante a realização dos direitos por ele instrumentalizados, não cumpre sua função constitucional, vez que representa barreira instransponível ao acesso à Justiça. (COSTA, 2015, p. 74).

A gestão processual do instituto, portanto, deve superar o dualismo pendular, deslocando o foco para o resultado útil e eficaz do instituto da recuperação, devendo o magistrado manter o equilíbrio do ônus igualmente suportado pelas partes para que os resultados sociais e relevantes da recuperação possam ser efetivamente maximizados (COSTA, 2015, p. 45).

Assim, atuando como gestor da coisa pública, cabe ao magistrado promover a eficaz administração do processo que, interfere diretamente no seu custo financeiro, pois a identificação correta dos pontos controvertidos na recuperação pode facilitar o andamento processual, bem como a celeridade e resolução dos conflitos existentes entre os credores e o devedor. A atuação do magistrado como espécie de mediador-gestor processual, aproxima as partes, bem como se insere na relação jurídica existente, podendo ser decisivo para a rápida e eficaz gestão dos ativos empresariais e judiciais (COSTA, 2015, p. 45).

Segundo a legislação de regência, permite-se ao juiz designar audiência para a colheita de informações das partes e demais interessados, sempre que entender necessário para a solução rápida e adequada das questões postas em juízo. E mais. Essa forma de gestão de processos é a que melhor atende aos princípios constitucionais da eficiência e da duração razoável do processo (COSTA, 2015, p. 76).

É possível melhorar a gestão processual nos fóruns independentemente de alteração normativa ou de investimentos no judiciário, basta que haja uma mudança direta dos 
aplicadores do direito no tocante à postura e mentalidade de condução do procedimento recuperacional, principalmente dos magistrados, que detém o controle estatal da jurisdição (COSTA, 2015, p. 47) permitindo que os jurisdicionados acordem os termos de condução dos procedimentos.

A recuperação judicial exige do Estado demasiada agilidade judicial, pois os atos processuais são fundamentais para sua preservação e desenvolvimento, devendo ocorrer no tempo razoável estipulado, viabilizando às empresas, a real oportunidade de se recuperarem judicialmente e, dos credores, o recebimento do que é devido, aplicando medidas e decisões judiciais construídas sob medida para as necessidades de ambas as partes na relação recuperacional (COSTA, 2015, p. 51).

Além de imprimir maior celeridade ao processo decisório, a Gestão
Democrática de Processos apresenta ainda outras vantagens: garante a
participação das partes e interessados no processo decisório, induz maior
comprometimento de todos aqueles que atuam no processo, assegura maior
transparência ao processo, propicia maior fiscalização sobre o andamento
processual e, ainda, franqueia aos interessados o fornecimento ao juízo de
informações relevantes e úteis sobre aspectos diversos do processo (como,
por exemplo, qual seria a melhor destinação de ativos específicos, dentre
outras), colaborando para a maior qualidade da decisão judicial. (COSTA,
2015, p. 76).

O juiz, ao adotar a gestão democrática em audiência, permite que as partes escolham as tarefas, isto é, o ônus de cada um equilibradamente, a fim de que seja possível atingir o resultado esperado, de forma rápida e adequada, por ambos os polos. Desta forma, o magistrado garantirá que todos em audiência tenham ciência dos atos a serem praticados, e das possibilidades de atuação para cada agente, não ensejando, posteriormente, a alegação de desconhecimento do que foi estabelecido ou de falhas individuais, induzindo maior comprometimento dos agentes atuantes do processo recuperacional (COSTA, 2015, p.55).

Vale ressaltar que, todos os atos estabelecidos e distribuídos em audiência, serão rigorosamente analisados na audiência de gestão seguinte, que é realizada para o acompanhamento dos passos processuais e andamento do processo, permitindo assim, a participação efetiva de todos os agentes integrantes da relação processual. Desta forma, conhecendo-se todo o andamento processual, bem como as responsabilidades distribuídas a cada parte, a tradicional postura resistente dos agentes vai gradativamente sendo substituída por uma colaboração mútua, democraticamente construída pelo Estado-juiz (COSTA, 2015, p. 56). 
O processo deixa de ser observado como a convergência de conflitos para, enfim, atingir a sua função política resolutiva de conflitos. Assim, a gestão democrática de condução do processo de recuperação permite que as partes deixem de se sentir parte do problema e passem a integrar a solução do conflito, permitindo que o procedimento possa transcorrer de forma mais rápida, eficiente e transparente, havendo uma significativa mudança na postura da condução processual.

As decisões que forem construídas em audiências de gestão democrática possuirão de forma acordada e justa os moldes dos casos concretos, ajustando-se às necessidades de cada caso e, distribuindo igualmente, as tarefas necessárias para se atingir o objetivo da recuperação judicial, atendendo da melhor forma os interesses dos credores, e da sociedade em geral. Atendendo da melhor forma os princípios constitucionais da eficiência e razoável duração do processo (COSTA, 2015, p. 56-57).

Assim, os interesses econômicos e sociais da sociedade em geral também são atingidos indiretamente pelo sistema de gestão democrática dos processos, já que a população não pode viver sem a utilização dos bens e serviços dos quais usufruem diariamente, preservando-se assim, a imagem social da empresa que, de igual forma, busca proteger os interesses dos credores, sem que haja o desmantelamento da sociedade economicamente viável (COSTA, 2015, p. 53).

A nova teoria sobre gestão democrática de processos tem sido aplicada com sucesso pelo juiz Daniel Carnio Costa na $1^{\text {a }}$ Vara de Falências e Recuperações Judiciais de São Paulo que, no processo de recuperação judicial da empresa LBR - Lácteos Brasil, desburocratizou a venda de 14 ativos da empresa, totalizando $\mathrm{R}$ \$ 533,4 milhões, proporcionando resultados satisfatórios que beneficiaram os credores e a sociedade em geral, permitindo a manutenção dos postos de trabalho e a reestruturação da empresa.

Processos de falência, como é o caso da VASP, e processos de recuperação judicial, como no caso da LBR, são exemplos de que a gestão democrática é capaz de tornar o processo de insolvência mais ágil, justo e eficaz. A aproximação das partes do processo decisório fez com que, em ambos os casos, todos os interessados se tornassem mais colaborativos e menos resistentes ao andamento do feito, na medida em que, através de deliberações e mediações, todos ficam mais conscientes dos objetivos do processo e de que o resultado positivo e esperado pela lei trará benefícios em geral ao funcionamento do sistema econômico e social além de beneficiar, em particular, todos os interessados diretamente no processo de insolvência. (COSTA, 2015, p. 76). 
A efetividade da gestão democrática foi tão impressionante que, Siderlei Oliveira, presidente da Confederação Brasileira Democrática dos Trabalhadores nas Indústrias de Alimentação (Contact), em reportagem nacionalmente divulgada: "Já participei de muitas negociações de falências e administração judicial de empresas e, em 40 anos de sindicalismo, é a primeira vez que vi esse resultado, com a manutenção de 2 mil empregos. Espero que esse tipo de recuperação judicial faça escola no Brasil". ${ }^{5}$

Portanto, a nova teoria da gestão democrática dos processos veio para superar o dualismo pendular de modo a deslocar o foco interpretativo do instituto da recuperação para a realização do resultado útil e eficaz desse sistema jurídico. Nesse contexto, e mais uma vez, deverá o Magistrado zelar pela equilibrada divisão de ônus entre credores e devedora, a fim de que os resultados sociais relevantes e decorrentes da recuperação da empresa possam ser maximizados, atribuindo ao processo de recuperação um caráter social e político além do instrumental.

\section{CONCLUSÃO}

O contínuo movimento de renovação do direito permitiu o surgimento de novos direitos sociais em razão das circunstâncias históricas, remodelando-se diante das oportunidades e suas conjunturas, os direitos perderam o caráter absoluto literal, adquirindo novas interpretações que ampliem ou reduzam seus valores, para que melhor atinjam suas finalidades, motivados por novas aspirações de plena eficácia da norma jurídica.

De semelhante modo, o novo Código de Processo Civil instituiu a possibilidade da realização de negócios jurídicos processuais atípicos, isto é, as partes em conjunto com o Juízo podem de forma colaborativa acordarem termos processuais e procedimentos para condução do processo judicial, de forma que, o processo possa se adequar da melhor forma aos interesses das partes.

Esta possibilidade jurídica surgiu em razão das partes, titulares do interesse sobre o direito material discutido na relação processual, serem os maiores interessados na condução procedimental do deslinde processual, razão pela qual, respeitando o autorregramento da vontade, decidirem como o procedimento se conduziria, respeitando-se as normas legais.

5 Disponível em: http://www.segs.com.br/segs/demais/47592-recuperacao-judicial-poupa-2-mil-empregos.html Acesso em: 12/05/2016. 
Paralelamente a este instituto processual, a recuperação superou sistemas jurídicos atrasados de insolvência, mudando-se o objeto de proteção, a Lei 11.101/2005 consagrou um novo instrumento processual para a recuperação econômica da empresa em crise, garantindo o prosseguimento das atividades por ela desenvolvidas, buscando-se a eficácia do direito aplicado como solução de problemas.

A correta e adequada interpretação referente ao sistema jurídico da recuperação judicial é notoriamente importante para a obtenção de suas finalidades sociais e econômicas. As tamanhas complexidades dos processos de recuperação não podem se tornar embaraços ao resultado útil e eficaz do instituto, sob pena de não cumprir sua função constitucional.

A gestão democrática de processos surge então como proposta de negócio jurídico processual atípico para a superação do dualismo pendular que ora alterna em defesa dos credores, ora em defesa dos devedores, nunca se resolvendo o conflito, mas postergando-o e acirrando-o num demorado tramite jurídico com elevado reflexo social.

Consequentemente, é possível um maior controle judicial da distribuição equilibrada de ônus entre devedora e credores, deslocando o foco interpretativo para a realização do resultado útil e eficaz desse sistema jurídico. Nesse contexto, deve o poder judiciário zelar pela equilibrada divisão de ônus entre as partes, a fim de que os resultados sociais relevantes e decorrentes da recuperação da empresa possam ser potencializados.

Dessa maneira, a gestão democrática processual da recuperação diminui consideravelmente o tempo que os jurisdicionados, precisam aguardar para receber uma decisão judicial final que seja efetivamente satisfatória, garantindo-lhes uma participação fluente no decorrer do procedimento, aproximando o Estado-juiz dos jurisdicionados, superando o dualismo pendular para uma distribuição equilibrada de ônus. O processo deixa de ser visto como uma convergência de conflitos para, consensualmente as partes acordarem o melhor andamento processual ao sistema jurídico, possibilitando a efetividade da função instrumental do serviço jurisdicional.

\section{REFERENCIAL BIBLIOGRÁFICO:}

AZEVEDO, Marcelo Cândido de. Função social e concorrência no direito de empresa. Piracicaba, São Paulo, 2007 
BOBBIO, Norberto. A era dos direitos. Tradução de Carlos Nelson Coutinho; apresentação de Celso Fafer. $6^{a}$ ed. Rio de Janeiro: Elsevier, 2004.

BRASIL. Constituição da república federativa do Brasil, de 05 de outubro de 1988. Diário Oficial da União. Brasília, 1988. Disponível em: http://www.planalto.gov.br/ccivil_03/ constituicao/constituicaocompilado.htm. Acesso em: 26 de janeiro de 2016.

BRASIL. Lei $\mathbf{n}^{\circ} \mathbf{1 1 . 1 0 1}$, de 9 de fevereiro de 2005. Regula a recuperação judicial, a extrajudicial e a falência do empresário e da sociedade empresária. Planalto. Brasília. Disponível em: http://www.planalto.gov.br/CCIVIL/_Ato2004-2006/2005/Lei/L11101. Acesso em: 15 fev. 20165.

BÜLOW, Oskar Von. Teoria das exceções e dos pressupostos processuais. Campinas: LZN, 2003.

CARNELUTTI, Francesco. Sistema de Direito Processual Civil. III. Tradução Hilton Martins Oliveira. São Paulo: Classic Book, 2000.

CHIOVENDA, Giuseppe. Instituições do Direito Processual Civil. Tradução Paolo Capittanio. Vol. 1. Campinas: Bookseller. 1998.

COELHO, Fabio Ulhôa. Comentários à nova lei de falências e de recuperação de empresas. São Paulo: Saraiva, 2005.

COELHO. Curso de direito empresarial: contratos, falência e recuperação judicial, volume 3. $-14^{\text {a }}$ Ed. São Paulo: Saraiva, 2013.

COMPARATO, Fábio Konder. A reforma da empresa. São Paulo: Saraiva, 1990.

COSTA, Daniel Carnio. Novas teorias sobre processos de insolvência e gestão democrática de processos. In: Comentários Completos à Lei de recuperação de empresas e falências. Daniel Carnio Costa. Volume I. Curitiba: Juruá. 2015.

COSTA. Reflexões sobre processos de insolvência: divisão equilibrada de ônus, superação do dualismo pendular e gestão democrática de processos. In Cadernos Juridicos. São Paulo. 2015

DIDIER JR. Fredie. Curso de direto processual civil: introdução ao direto processual civil, parte geral e processo de conhecimento/Fredie Didier Jr. - 19 ed. - Salvador: Ed. Jus Podivm, 2017.

DINAMARCO, Cândido Rangel. Instituições do direito processual civil. Volume I. São Paulo: Malheiros, 2001.

DINIZ, Maria Helena. Curso de direito civil brasileiro: direito de empresa. Volume 8 - São Paulo: Saraiva, 2008. 
GOLDSCHMIDT, James. Direito Processual Civil. I. Tradução Lisa Pary Scarpa. Campinas: Bookseller, 2003.

MAMEDE, Gladston. Direito empresarial brasileiro: empresa e atuação empresarial, volume 1. $-5^{\text {a }}$ Ed. São Paulo: Atlas, 2011.

MARTINS, Adriano de Oliveira. Recuperação da empresa em crise: a efetividade da autofalência no caso de inviabilidade de recuperação. $1^{a}$ Ed - Curitiba: Juruá, 2016.

NEGRÃO, Ricardo. A preservação da função social como objetivo da recuperação judicial da empresa. Direito Processual Empresarial. São Paulo: Elsevier, 2012.

NOGUEIRA, Pedro Henrique Pedrosa. Negócios Jurídicos Processuais: análise dos provimentos judiciais como atos negociais. 243f. Tese (Doutorado em Direito Processual Civil) - Universidade Federal da Bahia, Salvador, 2011.

OLIVEIRA, Celso Marcelo de. Comentários à nova lei de falências. São Paulo: IOB Thomson, 2005.

OLIVEIRA NETO, Olavo de. Curso de direito processual civil. 1 Edição. São Paulo: Editora Verbetim, 2015.

PACHECO, José da Silva. Das disposições preliminares e das disposições comuns à recuperação judicial e à falência. In: SANTOS, Paulo Penalva (Coord.). Rio de Janeiro: Forense, 2007.

SALOMÃO, Luís Felipe. A nova lei de recuperação de empresas: a declaração judicial da falência e a quebra requerida pelo próprio devedor. In: SANTOS, Paulo Penalva (Coord.). Rio de Janeiro: Forense, 2007.

TALAMINI, Eduardo. Um processo para chamar de seu: nota sobre os negócios jurídicos processuais. Informativo Justen, Pereira, Oliveira e Talamini. Curitiba. 2015.

TOMAZETTE, Marlon. Curso de direito empresarial: Falência e Recuperação de Empresas. Volume 3. - 2a . Ed. São Paulo: Atlas, 2012.

TZIRULNIK, Luís. Direito falimentar. $7^{\mathrm{a}}$ Ed. São Paulo: Editora Revista dos Tribunais, 2005 . 